\title{
BURN INJURY IN EPILEPTIC PATIENTS- A RETROSPECTIVE-DESCRIPTIVE STUDY IN A TERTIARY BURN CARE UNIT
}

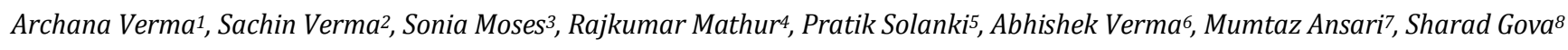

${ }_{1}^{1}$ Assistant Professor, (Neurology unit) Department of Medicine, MGMMC, Indore.

${ }^{2}$ Assistant Professor and Plastic and Reconstructive Surgeon, Department of Surgery, MGMMC, Indore.

${ }^{3}$ Associate Professor, Department of Surgery, MGMMC, Indore.

${ }^{4}$ Professor \& HOD, Department of Surgery, MGMMC, Indore.

${ }^{5}$ Resident, Department of Surgery, MGMMC, Indore.

${ }^{6}$ Resident, Department of Surgery, MGMMC, Indore.

${ }^{7}$ Resident, Department of Surgery, MGMMC, Indore.

${ }^{8}$ Resident, Department of Surgery, MGMMC, Indore.

ABSTRACT

\section{BACKGROUND}

The estimated annual burn incidence in India is approximately 6-7 million per year. Burn injury is a common but preventable cause of morbidity and mortality in India. In patients of epilepsy, the burn injury is far more severe than the any other comorbidities.

\section{MATERIALS AND METHODS}

This study design was a retrospective-descriptive study which was conducted in burn unit of MY Hospital, Indore with intention of identifying the risk factors for burn injury in epileptic patients. Study was conducted over a period of six years from the January 2009 to December 2015.

\section{RESULTS}

Maximum patients were of age group less than 40 years and most of them were females. All the burns were accidental in nature. Flame was the commonest mode of injury. Most of the patients sustained deep burns (60\%) of upper limb (62.8\%). Most of the patients had Generalised Tonic-clonic type of seizure and $88.5 \%$ of patients were not compliant to drug therapy.

\section{CONCLUSION}

Burn injuries sustained in epileptic patients are of very severe degree. These injuries are preventable if epileptic patients follow the general safety guidelines and remain stick to their treatment protocols.

\section{KEYWORDS}

Burn, Epilepsy, Drug Compliance, Risk Factor.

HOW TO CITE THIS ARTICLE: Verma A, Verma S, Moses S, et al. Burn injury in epileptic patients- A retrospective-descriptive study in a tertiary burn care unit. J. Evolution Med. Dent. Sci. 2017;6(94):6808-6811, D0I: 10.14260/jemds/2017/1474

\begin{abstract}
BACKGROUND
There are 50 million people living with epilepsy worldwide, and most of them reside in developing countries. About 10 million persons with epilepsy are there in India. ${ }^{1}$ Not all the patients receive appropriate treatment for their epilepsy. The magnitude of epilepsy treatment gap in India ranges from $22 \%$ among urban, middle-income people to $90 \%$ in villages. ${ }^{2}$ Because of this treatment gap the patient suffers from the attack. During the attack the patients have convulsion and loss of consciousness and if that attack occurs in vicinity of any burn agent they sustain burn injury. The burn injury sustained is deep because there is no attempt from the patient to escape from the injurious burn agent.
\end{abstract}

\section{MATERIALS AND METHODS}

The study design is a retrospective-descriptive study.

'Financial or Other Competing Interest': None.

Submission 26-10-2017, Peer Review 27-11-2017,

Acceptance 04-12-2017, Published 18-12-2017.

Corresponding Author:

Dr. Sachin Verma

\#8, Rajbada Chowk,

Indore-452001.

E-mail: drarchanaverma1@gmail.com

DOI: $10.14260 /$ jemds $/ 2017 / 1474$

\section{(c) $(1) \ominus$}

Thirty-five epileptic patients, admitted in the burn unit of MGM Medical College and MY Hospital from January 2009 to December 2015, were included in the study. Study was done with data collection done from the burn unit registry and medical record section. Variables like age, sex, mode of burn, severity of burn, site of burn, type of seizure and antiepileptic drug compliance were noted. Definite inclusion and exclusion criteria were laid and then patients were registered for study.

\section{Inclusion Criteria}

a. Proven cases of epilepsy with burn injury admitted in burn unit of MY Hospital, Indore.

b. Both males \& females were taken in this study.

c. Patients of all age groups were included.

\section{Exclusion Criteria}

All the epileptic patients who have been admitted in burn unit for management of burn contractures were excluded from the study.

Data was analysed using appropriate statistical method. As it was a retrospective study and confidentiality of patient was not disclosed at any point of time, there was no need to get the written consent. All the epileptic patients who are admitted in burn unit are subjected to a definite burn management protocol as per the burn unit criteria of our 
institute. Detailed history of the patient with respect to the burn injury and epilepsy is taken. Analysis of the percentage of burn injury i.e. total body surface area involved, degree or severity of burn injury, and other required parameters are noted down in history sheet. Detailed history about duration of epilepsy, treatment taken for same and abstinence from treatment of epilepsy is recorded. Opinion of neurological unit is sought for management of epilepsy and consensus treatment planned. State-of-the-art care is given for management. The team of plastic surgeons, neurologist, occupational therapist, physiotherapist, burn care surgeon, nurses and dressers were instrumental in management. These patients sustained severe burn, so they required many reconstructive surgeries.

\section{RESULTS}

Epileptic burn patients account for $1.1 \%$ of total burn admissions. Out of 3181 patients admitted in the burn unit, only 35 patients were diagnosed as epileptic patients. Twenty-seven of the epileptic burn victims were less than 40 years of age $(77.14 \%)$ and eight patients $(22.8 \%)$ were of more than 40 years of age. (Table-1).

Twenty-six patients (74.2\%) of epileptic burns were female and nine patients (25.6\%) were male. (Table-1).

Flame burn was the commonest (57.14\%) mode of injury in such patients followed by scald (37.14\%) and electric burns (5.71\%). (Table-2).

Most of the patients $(60 \%)$ sustained severe burns of third degree and more followed by second degree burn in $25.71 \%$ of patients. Severe burns were due to contact with flame for prolonged duration. $14.2 \%$ of patients had first degree burns. First degree burns were mainly due to scalds. (Table-3). Hand and upper limb burn was the commonest $(62.8 \%)$ site of burn injury. $25.71 \%$ of patients had lower limb and trunk injuries. Head, neck including the face was involved in four patients. (11.4\%). (Table-4).

Twenty-eight $(80 \%)$ patients had history of tonic-clonic seizure in the past for which they had received treatment. Absence seizure was prevalent in five patients. (14.2\%). Complex partial seizure was seen in two patients. (5.71\%) (Table-5).

Compliance to antiepileptic treatment was very poor. Ten patients $(28.5 \%)$ had received antiepileptic for duration of one year and then owing to some reasons or the other they stopped the treatment. Twenty-one patients (60\%) had received the antiepileptic for less than a year before stopping the treatment. Four patients developed the epileptic attack despite continuing the antiepileptic treatment. (Table-6).

$(\mathrm{N}=35)$

\begin{tabular}{|c|c|c|c|c|c|c|}
\hline \multirow{2}{*}{ Age Group } & \multicolumn{2}{|c|}{ Female 15 } & \multicolumn{2}{c|}{ Male 6 } & \multicolumn{2}{c|}{ Total } \\
\cline { 2 - 7 } & No. & $\%$ & No. & \% & No. & \% \\
\hline$<40$ years & 19 & 54.2 & 8 & 22.8 & 27 & 77.14 \\
\hline$>40$ years & 7 & 20 & 1 & 2.85 & 8 & 22.8 \\
\hline \multicolumn{3}{|c}{ Table 1. Age and Sex Distribution } \\
\hline
\end{tabular}

$(\mathrm{N}=35)$

\begin{tabular}{|c|c|c|}
\hline \multirow{2}{*}{ Mode of Injury } & \multicolumn{2}{|c|}{ Total } \\
\cline { 2 - 3 } & No. & \% \\
\hline Flame burn & 20 & 57.14 \\
\hline Electrical burn & 2 & 5.71 \\
\hline Scald burn & 13 & 37.14 \\
\hline Table 2. Distribution of Burn Patients According \\
to Mode of Burn \\
\hline
\end{tabular}

$(\mathrm{N}=35)$

\begin{tabular}{|c|c|c|}
\hline \multirow{2}{*}{ Severity of Injury } & \multicolumn{2}{|c|}{ Total } \\
\cline { 2 - 3 } & No. & $\mathbf{\%}$ \\
\hline First degree & 5 & 14.2 \\
\hline Second degree & 9 & 25.71 \\
\hline Third degree and more & 21 & 60 \\
\hline Table 3. Distribution of Burn Patients According \\
to Severity of Burn \\
\hline
\end{tabular}

$(\mathrm{N}=35)$

\begin{tabular}{|c|c|c|}
\hline \multirow{2}{*}{ Site of Injury } & \multicolumn{2}{|c|}{ Total } \\
\cline { 2 - 3 } & No. & \% \\
\hline Hand and upper limb & 22 & 62.8 \\
\hline Head and neck including face & 4 & 11.4 \\
\hline Lower limb and trunk & 9 & 25.71 \\
\hline Table 4. Distribution of Burn Patients According \\
to Site of Burn \\
\hline
\end{tabular}

$(\mathrm{N}=35)$

\begin{tabular}{|c|c|c|}
\hline \multirow{2}{*}{ Type of epilepsy } & \multicolumn{2}{|c|}{ Total } \\
\cline { 2 - 3 } & No. & $\mathbf{\%}$ \\
\hline Generalised Tonic-clonic seizure & 28 & 80 \\
\hline Absence seizure & 5 & 14.2 \\
\hline Complex partial seizure & 2 & 5.71 \\
\hline Table 5. Distribution of Burn Patients According \\
to Type of Seizure \\
\hline
\end{tabular}

$(\mathrm{N}=35)$

\begin{tabular}{|c|c|c|}
\hline \multirow{2}{*}{ Type of antiepileptic drug compliance } & \multicolumn{2}{|c|}{ Total } \\
\cline { 2 - 3 } & No. & $\mathbf{\%}$ \\
\hline Taken for 1 year and then stopped & 10 & 28.5 \\
\hline Taken for less than 1 year and stopped & 21 & 60 \\
\hline Compliant but still sustained burn & 4 & 11.42 \\
\hline Table 6. Distribution of Burn Patients According to \\
Antiepileptic Drug Compliance \\
\hline
\end{tabular}

\section{DISCUSSION}

Epileptic patients sustain severe burn injuries. Burning is a potentially a fatal hazard faced often by poorly controlled epileptics. $^{3}$ Rationalised treatment of epilepsy requires selection of combination of appropriate antiepileptic with optimisation of dosage. Specialist advice is must for treatment of refractory cases. An association of burn and epileptic fits associated with cysticercosis is mentioned by Subianto et al. ${ }^{4}$ Literature also mentions about grass-skirt burns sustained due to fall into fore during epileptic attack. ${ }^{5}$ Association of burn and epilepsy is mentioned by various authors across the twentieth century.6,7,8,9 Predictors, risk factors and epidemiological indicators have been studied in various studies.10,11 Our study has shown the following determinants of burn injury in epileptic patients.

\section{Age and Sex Distribution}

Usually the age-specific incidence rates of epilepsy show the bimodal distribution.12,13 Bimodal distribution is the two peak distribution of epilepsy in patients. In most studies in developing countries, prevalence of epilepsy remains stable in the third and fourth decades and typically drops after the fifth decade of life. ${ }^{14}$ This is in accordance to our observation of $77.14 \%$ of epileptic burn cases occurring before the fourth decade of life. 
$71.3 \%$ of our patients were females, this is in accordance to preponderance of female burns in study of Gowri et al ${ }^{15}$ and Gupta et al. ${ }^{16}$ However, literature mentions that absolute difference in gender specific prevalence is minimal among epileptic patients. ${ }^{14}$ The most extreme example of a male excess was reported in a study conducted in India, in which prevalence of males (5.1 per 1000) was significantly higher than females (2.2 per 100) (Bharucha et al., 1988).14 Preponderance of females in our study can be attributed to the fact that females are in vulnerable proximity to the burn agents owing to their household activities like cooking and abundance of such agents in households. Males usually are working outside the home and they have less chances of exposure to the burn agents. Males who work in electric power sector are usually susceptible to electrical injury.

\section{Mode of Injury}

Flame burn is the commonest cause of burn injury in our study of epileptic patient. Similar modes of burn injury were obtained in other studies. ${ }^{16,17}$ MV Singh et al ${ }^{18}$ also showed higher incidence of flame and scald burns in their study. Scalds are usually seen in children. Epileptic patients suffer from scald when they develop epileptic attack in the bathrooms or while boiling. Mzezewa $\mathrm{S}^{19}$ also mentioned that $98 \%$ of their burn victims were result of flame and scalds. Cheng et al 20 also mentioned that most common cause of burn was flame (67.9\%), this is in accordance to our study. Boschini L et al ${ }^{21}$ mentioned that flame injury was the most common mode of burn in patients with seizure disorder, whereas scalds predominated among patients without seizure disorder. Jang $\mathrm{YC}$ et $\mathrm{al}^{22}$ in their study obtained scalding as the most common injury and this finding is dissimilar to our study. Josty IC ${ }^{9}$ in their study observed that majority of burns were due to scald injury and were sustained in domestic settings. This prevalence of scald is also not in accordance to our study.

\section{Severity of Burn}

In our study, we obtained that most (60\%) of the burns were of marked severity (third degree or more). This is not seen in usual burn injuries. Haisheng Li et al 23 showed an incidence of $40.1 \%$ of full thickness burn and that too was mainly due to flame. Patients with full thickness burn require operative intervention. Burton $\mathrm{KR}$ et $\mathrm{al}^{24}$ obtained that the majority of their patients were admitted with second-degree burns (48.7\%). Greater penetration of heat energy in epileptics may be attributed to the fact that epileptic burn victims become unconscious at the time of accident and there is hardly any attempt to escape from the burn. The contact time with the burn agent is more and so is the severity of burn. Bystanders usually take the victim out of dangerous substance.

\section{Site of Burn}

Hand and upper limb burns are common (62.8\%) sites of burn injury in epileptic patients. This is due to the fact that during the attack patients fall in the vicinity of burning agents and sustain the burn. Sometimes burns sustained are only on the face due to sudden fall over the burn agent. Haisheng Li et $\mathrm{al}^{23}$ also mentioned that limbs were the most common burn sites accounting for $72.1 \%$ of all admissions. Yao $Y$ et $\mathrm{al}^{25}$ obtained that $31.98 \%$ of victims involved multiple body site burns in terms of injured body region. Jang YC et al 22 in their study mentioned typical involvement of upper limb and lower limb.

\section{Type of Seizure}

Generalised Tonic-clonic Seizure was the commonest epilepsy in burn patients diagnosed by neurological unit of our institute. This type of epilepsy pattern is seen in other studies also. ${ }^{26}$ Similarly, our incidence of partial seizure was comparable to standard pattern. Boschini L et al ${ }^{21}$ in their study found that patients with epilepsy have higher incidence and severity of burn injuries. Jang YC et $\mathrm{al}^{22}$ in their study mentioned that in epileptic burns, the most commonly associated seizure type was generalised tonic-clonic followed by absence and complex partial. This is in accordance to our study. They also mentioned that seizures occurred at home, while the patients were conducting daily household chores.

\section{Compliance of Antiepileptic Drugs}

Patients who sustained the burn injury during epileptic attack were those who already were known/diagnosed epilepsy cases who were not taking the full treatment. Almost $90 \%$ were treatment-gap patients. If they had received the proper treatment, they would not have sustained the attack and thence the burn. Few patients had epilepsy despite on treatment and they needed optimisation of dosage or change of drug therapy. Jang $\mathrm{YC}$ et $\mathrm{al}^{22}$ in their study suggested specific passive as well as active recommendations based on the epidemiologic features of study population. They also mentioned that to implement a successful burn injuryprevention program, patients with epilepsy should be better recognised as a high-risk group. Jost J et al27 in their study mention that the treatment gap exceeds $75 \%$ in most lowincome countries, and could be even higher in rural areas. Reasons for that are low accessibility, availability, and/or affordability, lack of trained medical personnel and the associated beliefs and stigma.

\section{CONCLUSION}

Burn injuries in epileptic patients are very severe. This can lead to a lot of functional and cosmetic deformity that can make their lives more difficult. Best course of action is to prevent such injuries. Small measures like avoiding open flame and kerosene and use of microwave for cooking and abiding to treatment regime can be good preventive measures for such high-risk patients. It is the responsibility of epilepsy care providers and burn prevention and management team to formulate a national programme to prevent and cure epileptic burns.

\section{REFERENCES}

[1] Akhtar MS, Ahmad I, Khan AH, et al. Burn injury in epileptic patients: an experience in a tertiary institute. Ann Burns Fire Disasters 2014;27(3):126-9.

[2] Meyer AC, Dua T, Ma J, et al. Global disparities in the epilepsy treatment gap: a systematic review. Bull World Health Organ 2010;88(4):260-6.

[3] Durward WF, Harrington MG. Burning and the inadequate management of epilepsy. $\mathrm{Br}$ Med J 1979;2(6199):1218. 
[4] Subianto DB, Tumada LR, Margono SS. Burns and epileptic fits associated with cysticercosis in mountain people of Irian Jaya. Trop Geogr Med 1978;30(3):2758.

[5] Barss P, Wallace K. Grass-skirt burns in Papua New Guinea. Lancet 1983;1(8327):733-4.

[6] De Castro AB, Zegri IV, Galvez C del F. Burns and epilepsy. An analytical study. Cirugia Plastica IberoLatinomericana 1978;4:307-14.

[7] Bhatnagar SK, Srivastava JL, Gupta JL. Burns: a complication of epilepsy. Burns 1977;3(2):93-5.

[8] Maisels DO, Corps BVM. Burned epileptics. Lancet 1964;1:1298-301.

[9] Josty IC, Narayanan V, Dickson WA. Burns in patients with epilepsy: changes in epidemiology and implications for burn treatment and prevention. Epilepsia 2000;41(4):453-6.

[10] Spitz MC, Towbin JA, Shantz D, et al. Risk factors for burns as a consequence of seizures in persons with epilepsy. Epilepsia 1994;35(4):764-7.

[11] Buck D, Baker GA, Jacoby A, et al. Patients' experiences of injury as a result of epilepsy. Epilepsia 1997;38(4):439-44.

[12] Banerjee TK, Ray BK, Das SK, et al. A longitudinal study of epilepsy in Kolkata, India. Epilepsia 2010;51(12):2384-91.

[13] Radhakrishnan K, Pandian JD, Santhoshkumar T, et al. Prevalence, knowledge, attitude, and practice of epilepsy in Kerala, South India. Epilepsia 2000;41(8):1027-35.

[14] Banerjee PN, Filippi D, Allen Hauser W. The descriptive epidemiology of epilepsy-a review. Epilepsy Res 2009;85(1):31-45.

[15] Subrahmanyam M. Epidemiology of burns in a district hospital in western India. Burns 1996;22(6):439-42.

[16] Gupta M, Gupta CK, Yaduvanshi RK, et al. Burn epidemiology: the pink city scene. Burns 1993;19(1):47-51.
[17] Shankar G, Naik VA, Powar R. Epidemiological study of burn injuries admitted in two hospitals of north Karnataka. Indian J Community Med 2010;35(4):50912.

[18] Singh MV, Ganguli SK, Aivanna BM, et al. A study of epidemiological aspects of burn injuries. Med J Armed Forces India 1996;52(4):229-32.

[19] Mzezewa S, Jonsson K, Aberg M, et al. A prospective study on the epidemiology of burns in patients admitted to the Harare burn units. Burns 1999;25(6):499-504.

[20] Cheng W, Yan-hua R, Fang-gang N, et al. Epidemiology of 1974 burn patients at a major burn center in Beijing: a nine-year study. J Burn Care Res 2012;33(5):e228-33.

[21] Boschini LP, Tyson AF, Samuel JC, et al. The role of seizure disorders in burn injury and outcome in SubSaharan Africa. J Burn Care Res 2014;35(6):e406-12.

[22] Jang YC, Lee JW, Han KW, et al. Burns in epilepsy: seven years of experience from the Hallym burn center in Korea. J Burn Care Res 2006;27(6):877-81.

[23] Li H, Yao Z, Tan J, et al. Epidemiology and outcome analysis of 6325 burn patients: a five-year retrospective study in a major burn center in Southwest China. Sci Rep 2017;7:46066.

[24] Burton KR, Sharma VK, Harrop R, et al. A populationbased study of the epidemiology of acute adult burn injuries in the Calgary health region and factors associated with mortality and hospital length of stay from 1995 to 2004. Burns 2009;35(4):572-9.

[25] Yao Y, Liu Y, Zhou J, et al. The epidemiology of civilian inpatients' burns in Chinese military hospitals, 20012007. Burns 2011;37(6):1023-32.

[26] Newale S, Bachani DS. Demographic characteristics of epilepsy patients and antiepileptic drug utilization in adult patients: results of a cross-sectional survey. Neurol India 2016;64(6):1180-6.

[27] Jost J, Millogo A, Preux PM. Antiepileptic treatments in developing countries. Curr Pharm Des 2017. 